54 | Tropelías. Revista de Teoría de la Literatura y Literatura Comparada, 26 (2016)

Rosalía Torrent Esclapés

\title{
MAR ARZA: LA INQUIETANTE LUZ DE LA PALABRA
}

\author{
Rosalía TORRENT ESCLAPÉS \\ Universitat Jaume I de Castellón \\ torrent@uji.es
}

$\mathrm{E}$ mpleo siempre con mucha prudencia la palabra «belleza». He aprendido que su uso debe ser comedido, porque pocas obras u objetos, artísticos o no, soportan la extraordinaria carga semántica del término. Sin embargo, la primera sensación que tuve frente a los trabajos de Mar Arza (concretamente ante Nada era la herida y las serie Asombros) fue precisamente que me encontraba ante unos cuerpos sensibles que se enmarcaban perfectamente en las sensaciones que produce en nosotros aquella palabra. La quietud - pero también el ritmo-, la sobriedad, la forma elegante, los tonos sosegados, se adscribían inicialmente al significado que la cultura occidental ha otorgado al concepto de lo bello.

Pero pronto se acaba, frente a las obras de esta creadora, el espejismo de lo visual. La progresiva visita al universo de la artista, el decodificamento de su lenguaje, la inmersión en sus misterios, hacen que - aun no perdiendo por completo su inicial efecto purificador - sus obras vayan ganando en una sensual pasión fuertemente incompatible con esa categoría estética central que es la belleza. El mundo de la paradoja encuentra en Mar un lugar privilegiado, tanto por esta dicotomía visual como, sobre todo, por unas obras mitad poema plástico mitad pintura poética, pues, como afirma Irene Gras: «Su trabajo no juzga ni concibe la separación entre arte y literatura, más bien se entrelazan [...] no hay diferencia entre ambas porque son iguales, se consideran distintos idiomas para un mismo pensamiento» (2013: 47). En cierta manera, el ut pictura poesis horaciano.

Mar Arza (Castellón, 1976) es definitivamente una artista de la imagen y la palabra. Nada era la herida, del año 2005, y En lugar de nada, de 2005-2006, que en realidad percibimos como un continuum, se perfilan como una evolución de unos trabajos previos donde el libro o su página (y en ellos las palabras) ya habían adquirido tintes de una gran carga plástica. Baste recordar la instalación de 2002 ...letterscape... (with gleanings by the way) en la que, a partir de un libro encontrado en una de sus incursiones en librerías de viejo, Saunterings in Bookland (Pasear por el territorio de los libros), nos propone un metafórico recorrido a través de una instalación de luz y de palabras. El libro en sí, con una expresiva portada de un caminante-lector, recogía un conjunto de textos donde diversos autores expresaban su amor a los libros: 
No es difícil entender que tanto el libro como el título sedujesen a una artista desde hace tiempo interesada en ir elaborando los pliegues y repliegues de esta relación amorosa. La instalación se abría con esta invitación a iniciar metafóricamente la lectura como una caminata por un, traducido literalmente, «paisaje de letras» (letter-landscape=letterscape) (Bassas, 2003: 245; la traducción es mía).

El libro se convierte en el eje de esta instalación donde la luz se une a las palabras, desgajadas de sus páginas y acogidas por diversas bombillas, metáfora quizá del momento de iluminación que Graham Wallas subrayara como propio del proceso creativo. Una expresiva y simbiótica manera de aunar sabiduría e imagen plástica con la remisión constante a las formas tipográficas unidas a través del sentido. Mar Arza, en esas obras, ya se definía como la amante del libro que podemos no solo leer sino interpretar plástica y emotivamente. Junto a esta obra podemos recordar también aquellas otras realizadas con páginas volumétricas en las que se ocultan o magnifican unos tipos de imprenta sin los cuales los libros, simplemente, no serían.

Volvamos, sin embargo, a esos trabajos de 2005-2006 en cuyo título aparece, como un doble eco, la palabra «nada». ¿A qué se refiere Arza con ese término? ¿Qué nos quiere decir o transmitir? Pronto nos lo desvelará, al menos parcialmente: esta nada, su nada, parte de la Nada literaria de Carmen Laforet en esa novela que dio una - curiosamente premiada- bofetada a la España de la inmediata posguerra. Pero «la nada es mucho», le había dicho Kandinsky a un alumno que, intentando reflejarla (y pillar en falta al maestro), había realizado un cuadro completamente blanco. Pero, decíamos, «la nada es mucho», y así el maestro ruso - afirma el estudiante-

[...] se tomó mi cuadro muy en serio. Lo colocó delante de nosotros y dijo: «Las medidas del cuadro están bien. Hablan de lo terrenal. El color terrenal es el rojo. ¿Por qué ha escogido usted el color blanco?» Yo contesté: porque la superficie blanca representa la Nada. «La Nada es mucho», dijo Kandinsky. «De la Nada creó Dios el mundo. Y nosotros queremos utilizar un poco esa fuerza creadora y crear de la Nada un pequeño mundo». Entonces cogió pintura y un pincel y puso sobre la superficie blanca una mancha roja, una amarilla, una azul y dejó alrededor una sombra verde clara. Y de repente, allí había un cuadro, un cuadro de verdad, un cuadro espléndido (Schreyer, 1956; cit. en Martínez Benito, 2011: 8).

También la nada es mucho para Mar Arza, tanto que la construye y reconstruye a partir de la propia palabra, como Wassily Kandinsky la reconstruyó a través de la pintura. Quizá nadie como este pintor comprendió su sentido; nadie como él la atavió de color. La nada — dicen— se viste, como el silencio, de color blanco. Y aquí de nuevo Mar Arza, que envuelve de blanco sus lugares. En efecto, blanca es la imagen que la artista nos devuelve en estas primeras obras; el blanco quizá (y seguimos con Kandinsky) como símbolo de un mundo

[...] donde han desaparecido todos los colores como cualidades y sustancias materiales. Ese mundo está tan por encima de nosotros que no nos alcanza ninguno de sus sonidos. De allí nos viene un gran silencio, que representado materialmente parece un muro frío, infranqueable, indestructible e infinito. Por eso el blanco actúa sobre nuestra alma como un gran silencio absoluto (Kandinsky, 1911: 85-86),

pero -continúa el artista ruso-: «El blanco suena como un silencio que de pronto puede comprenderse» (Kandinsky, 1911: 86). Y así también, de pronto, comprendemos la nada de Mar Arza, una vez descifrados sus blancos espectros y silencios. Pasemos a la acción. 


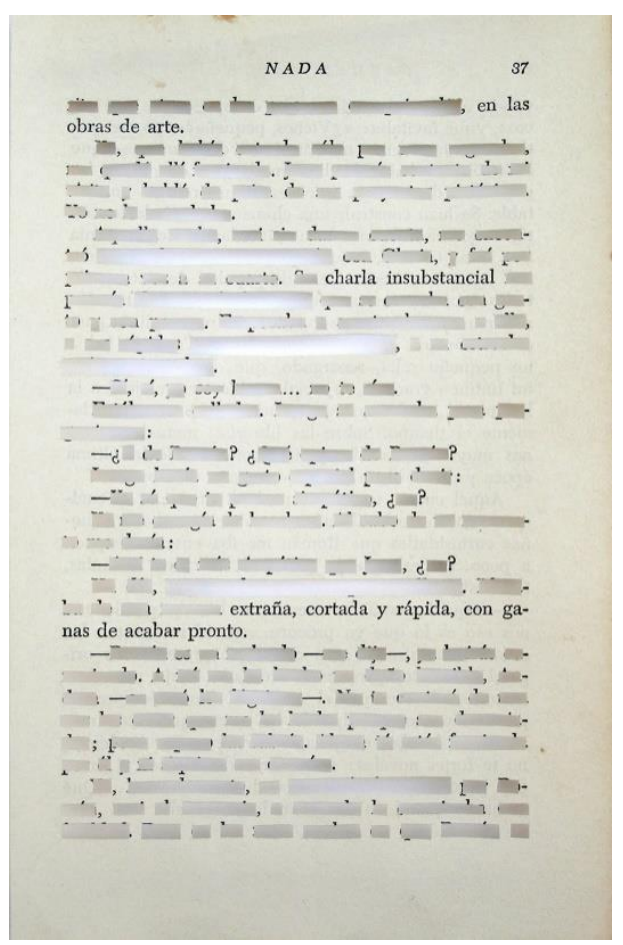

Fig. 1. Serie Nada era la herida. Imagen cortesía de la artista y de la Galería Pilar Dolz.

Nada era la herida es un conjunto de dos piezas simétricas, en la primera de las cuales aparece una página de un libro (de la Nada de Carmen Laforet en una de sus primeras ediciones) en la cual casi todas las palabras están cubiertas por trazos blancos excepto el mismo encabezamiento de la novela, «Nada», y la siguiente serie de palabras: «en las obras de arte», «Su charla insubstancial» y «extraña, cortada y rápida, con ganas de acabar pronto». ¿Ha querido Arza, a modo de cadáver exquisito, explorar las posibilidades de unas palabras en cuya elección, de manera necesaria, aparece el azar? Un azar previamente orientado, ciertamente, pero azar al fin y al cabo. Arza/Azar, ¿es otro juego? «Nada en las obras de arte Su charla insustancial extraña, cortada y rápida» - leemos de un tirón-. E interpretamos: lo vacío en el arte, lo que a veces se nos presenta como una conversación desganada, entrecortada, llena de interrogantes. Sería, esta última, una posibilidad de lectura de este atípico poema visual.

Pero otro interrogante más fuerte toma consistencia: si éstas son las palabras que perviven, ¿cuáles son las que la artista ha ocultado? En la novela de Laforet (y en la página escogida por Arza) el personaje Juan pinta sin ningún talento a una Gloria que, desnuda, logra adquirir por mor de su piel perfecta, un aspecto de sutil inteligencia: «Algo que en sus ojos no lucía nunca. Esta llamada del espíritu que atrae en las personas excepcionales, en las obras de arte.» (Laforet, 1991: 36-37). La protagonista de la novela, Andrea, que ha advertido tal transformación, acude ¿a la amistad? de la mujer desnuda:

Aquella noche, casi sin darme cuenta, me encontré iniciando una conversación con Gloria, y fui por primera vez a su cuarto. Su charla insubstancial me parecía el rumor de lluvia que se escuchaba con gusto y con pereza [...]. Un día, impensadamente, se puso a llorar. Lloraba de una manera extraña, cortada y rápida, con ganas de acabar pronto (Laforet, 1991: 37; las cursivas son mías).

Todas las frases «salvadas» en la página aluden a Gloria, la mujer desvalida que finalmente se quedará en casa para soportar todos los golpes de su marido, mientras la protagonista, Andrea, tiene la oportunidad de marchar. Gloria, seguramente, tendrá mucho que decir en esta historia de frases canceladas que parte de los personajes inmersos en ese mundo asfixiante de la Nada de Carmen Laforet.

No sólo lo que se exhibe, sino lo que ha quedado oculto, conforman el todo de esta obra peculiar que encuentra su segunda parte (recordemos que nos encontramos ante un díptico) en un papel con cientos de incisiones cuadrangulares de tamaños diferentes que nos llevan también a palabras recortadas y definitivamente canceladas. «Desde sus inicios, el corte tiene un especial protagonismo en las delicadas obras de Mar Arza, un dato que me ha llevado a sospechar el substrato radical de su 
obra», dice Assumpta Bassas Vila (2013: s/p). En efecto, hay siempre algo de radical en aquel o aquella que empuña bisturí o cuchillo, más todavía si finalmente, como hará la artista más tarde en Femme Couteau (2011-2013), decide realizar físicamente el objeto que hiere. Analiza Bassas el hipotético comportamiento diferente del corte en la obra de arte si éste es realizado por artistas hombres o artistas mujeres, subrayando la posibilidad de una raíz histórica femenina en determinados modos de uso de estos procedimientos. En cualquier caso, las cicatrices sobre el papel se repiten en las obra de la artista, aunque curiosamente la aparente gravedad del hecho no tiene una correlación con la visualización que llevamos a cabo sobre ella. A pesar de todo, lo bello gana a lo siniestro.

Un poco más adelante volveremos sobre esta Mujer Cuchillo. Ahora continuemos con la nada, o En lugar de nada, un espacio en el que la artista continúa creando «metáforas visuales a partir del libro y la lectura, a medio camino entre el poema visual u objetual, el lenguaje de la escultura y las instalaciones» (Bassas, 2007: s/p) y donde

\footnotetext{
El libro, sometido a un proceso de metamorfosis, deja de ser puro contenedor de signos y palabras. Palabras recortadas, divididas, quemadas... Desocupación —exilio de la palabra-, que da paso a lo inmaterial. La ausencia, la nada, invaden el libro. Palabra escindida transformada en luz. Luz blanca — principio y fin de la vida - visible en sus extremos. Segmento acotado. Silencio. Final del trayecto (Bruguera, 2007: s/p).
}

De nuevo con Laforet de fondo, las palabras ahora aparecen recortadas en decenas de páginas del libro fetiche, de las que de nuevo rescata unas pocas en búsqueda de un significado más íntimo que compartido. Me sorprende de esta instalación, no ya este lúcido recurso, sino la disposición de las páginas, exentas en los muros, dejando que las luces y las sombras de los huecos que en ellas habitan, se dejen sentir en las paredes.

Y sorprenden también las fotografías de fragmentos de piel «con la trama de sus cortes» (Del Olmo Campillo, 200506) que se instalan a su lado. De cerca, esta piel, rememora las cicatrices que ya viéramos, en papel, en Nada era la herida. La piel en toda su infinita cercanía, tan lejos de aquellos que pensaron en un mundo futuro donde nuestra propia carne, nuestra epidermis «olvidando las rugosidades de los brotes de los árboles, tenderá a parecerse al acero circundante» (Marinetti, 1911: 320; la traducción es mía). El

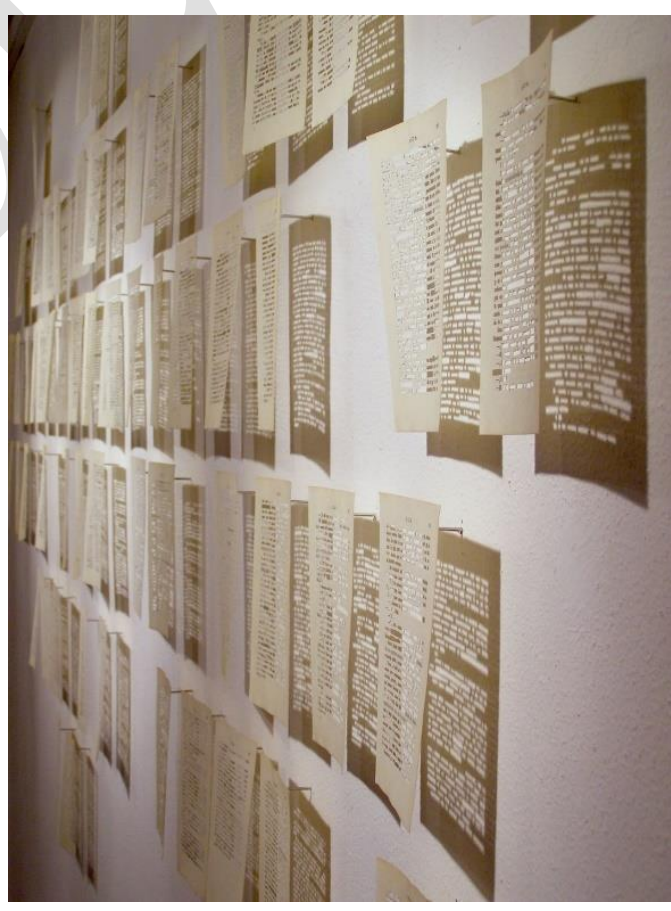

Fig. 2. Serie En lugar de nada. Imagen cortesía de la artista y de la Galería Pilar Dolz. Marinetti tecnológico situado en las antípodas de la tibieza herida de Mar Arza.

Es quizá el momento de pasar de la cicatriz al cuchillo y a una obra mucho más reciente como es Femme Couteau [after L. B.]. Esas iniciales (lo habrán adivinado) pertenecen a la escultora Louise Bourgeois, quien en su momento hiciera su Femme Couteau, esa extraordinaria pieza donde se adivina tanto un símbolo fálico-arma como unos genitales femeninos. Se pregunta Bourgeois: «¿Por qué las 
mujeres se convierten en mujeres cuchillo? No nacieron como tales. Se les hizo así a través del miedo. En Femme Couteau la mujer se convierte en un cuchillo, es una figura defensiva. Para defenderse, se identifica con el pene» (cit en Seiberling, 1974: 56). Al fin y al cabo, la artista francesa dijo una vez que cuando se encontraba de mal humor sentía el deseo de cortar cosas (Bourgeois, 1992: 123). No es el mal humor, sin embargo, lo que guía a Mar Arza en su deseo de cortar cosas, sino una exploración de la piel del papel y un íntimo sentido poético. En su versión, frente a la violencia que se percibe en la de Bourgeois, quiso «transformar un objeto hiriente, como son unos cuchillos, en algo frágil y delicado, hecho en porcelana, a los que añadí palabras en el filo, significando que ciertas agresiones

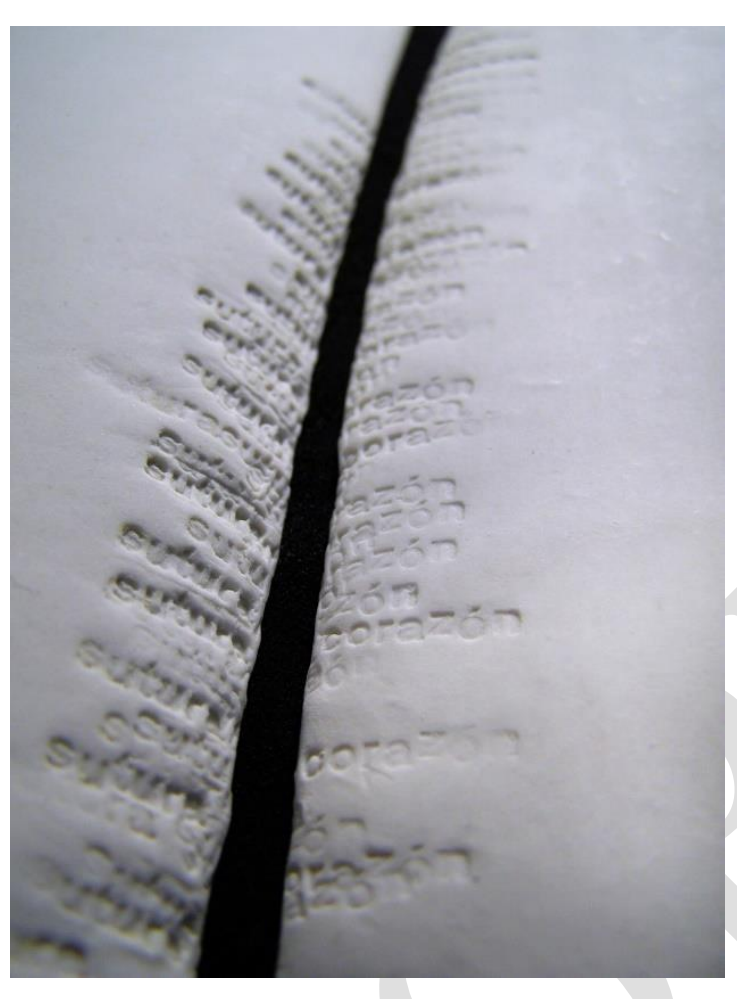

Fig. 3. Serie Femme couteau. Imagen cortesía de la artista y de la Galería Pilar Dolz. podrían evitarse o ser resueltas a través de la comunicación» (cit. en Gras, 2013a).

En la primera versión que realizó de los cuchillos, las palabras se situaban, recortadas, sobre su mismo filo. Y una de esas palabras es, significativamente «silencio», ese silencio que se une a la nada. La nada y el silencio. Apoyándolas, la palabra «pureza» también se asoma a los bordes de unos delicados instrumentos cortantes. Y, remachando, la palabra «quietud» jugando con su antítesis: «inquietud», repetida, y esta vez inscrita en el filo con tipografía de máquina de escribir. Mar Arza no juega con las palabras, sino con unas determinadas palabras, que le ayudan a potenciar un mensaje difícil de interpretar pero que intuimos perfectamente meditado y coherente. Y construido con el hilo de un silencio que habla. De ahí los cuchillos enfrentando Corazón-sutura. Encerrados en su estuche de madera y fondo de terciopelo.

$\mathrm{Al}$ cuchillo, si queremos observarlo desde un punto de vista de género, podemos otorgarle dos significados: el cuchillo-puñal, que -secularmente unido a lo masculino-agrede y mata; y el que se une a la preparación de alimentos y a lo considerado como femenino. Y es precisamente esa dicotomía generada desde el discurso del poder la que muchas artistas se han propuesto cuestionar. Quizá Hannah Hoch, con su Corte con el cuchillo de cocina Dadá en el vientre cervecero de la última época cultural de la Alemania de Weimar, estaba jugando con lo doblemente simbólico: un cuchillo de cocina «empuñado» por una mujer atravesando con ironía los símbolos caducos del poder y el vientre del que se cree macho dominante y luce sin prejuicios su borrachera de grasa homicida. En el centro de la obra, sin embargo, la cabeza de la expresionista Käthe Kollwitz, que aparece flotando sobre los brazos extendidos de la bailarina Nidda Impekoven, serían los símbolos de las mujeres comprometidas y libres. 
Muchas mujeres, después, en el ámbito del feminismo, recogieron el motivo del corte y de las incisiones de manera más o menos brutal o al menos singular: aún asombran los cortes brutales sobre su propio cuerpo de Gina Pane o, en la actualidad, las incisiones que se provoca Martha Amorocho. Pero es muy otro el lugar en el que se sitúa Mar Arza. Sus cuchillos conjugan la delicadeza con lo explícito, y son ante todo (o al menos yo lo percibo así) fecundos hallazgos vehiculados por la forma sensible de la palabra mecánicamente escrita.

Toda obra de arte que no se deleite únicamente en la pura abstracción cuenta una historia, o al menos un instante petrificado de una historia personal. Pero, vehiculando los significados, se sitúa una forma sin la que éstos no serían arte sino simplemente discurso. Es esa forma, también, lo que me impacta del trabajo de esta artista. Visualmente me emocionan las páginas de libros con palabras tachadas de las que, sin embargo, se conservan rabillos que configuran otro peculiar lenguaje que a veces adquiere todos los tintes de una partitura. También me parecen plausibles hallazgos como Incís (de nuevo el corte y lo que se sitúan detrás de él). Inevitablemente vamos al espacialista Fontana, quien en Concetto Spaziale-Attesa, de 1964-65 traza, en el lienzo en blanco, una herida que le recorre verticalmente. En Incís, idéntica herida, pero unos bordes que no dejan entrever el vacío, sino que de ellos se desliza — piel rasgada - un fragmento de papel donde de nuevo se inscriben las palabras. En cualquier caso, en ambos asistimos a la violencia del corte en un espacio poético. Pero, frente al vacío de Fontana, la palabra de Arza como parte de una nada que de pronto se ha puesto a hablar.

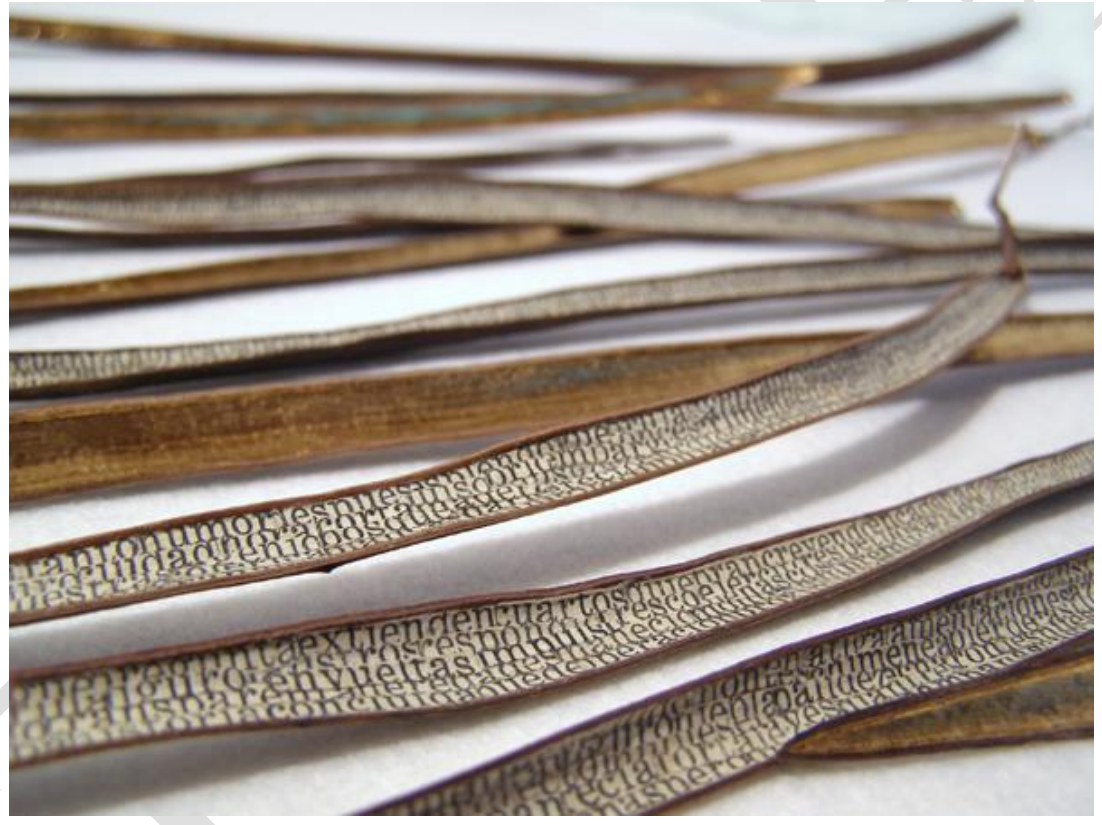

Fig. 4. Serie Femme gaine. Imagen cortesía de la artista y de la Galería Pilar Dolz.

Junto a su Femme Couteau, nuevamente Mar Arza bautiza una de sus series con la palaba «Mujer», en Femme Gaine, o Mujer vaina, de 2012. Es posiblemente ésta una de sus obras más definitivamente vinculadas a una posición de género. La descripción simple de la obra no podría darnos una idea de la poesía que se encierra en ella. Dentro de vainas - a veces cubiertas con pan de oro- de un árbol llamado catalpa, que da sus frutos en otoño, la artista introduce de nuevo una suerte de palabras. Nuestra actual palabra vaina viene de la palabra latina vagina, que significaba precisamente vaina, en el doble sentido de la cáscara de las semillas y la funda de la espada (de ahí seguramente su connotación sexual, que más tarde adoptaría plenamente). En cualquier caso, si atendemos a la etimología latina, «estos objetos preciosos adquieren además la connotación añadida de invocar el abrigo materno con el revulsivo implícito en el determinismo biológico del cuerpo de la 
mujer» (Arza, 2011-13a; la traducción es mía). La vaina, el interior del cuerpo de la mujer, dador de vida, dador del lenguaje y de la palabra (no en vano hablamos de lengua materna) adquiere esa evidente doble simbología. Más todavía: el pan de oro, en relación con la iluminación de las imágenes medievales, suma a las imágenes una vertiente espiritual, cualidad ésta muy presente en los trabajos de la artista.

Siguiendo con el concepto envolvente de vaina, estructura frágil y mistérica, encontramos un nuevo trabajo de Mar Arza, esta vez resuelto a través de un video, Nora (2012), cuyo nombre remite a la heroína de la Casa de muñecas de Ibsen. Esta vez, la hamaca-vaina encierra como su semilla a una mujer sin dejar «esparcir simientes» (Arza, 2011-13b; la traducción es mía). Nora, que tendrá que abandonarlo todo para lograr ser ella misma, quiere abandonar la casa-prisión que la retuvo. Su marido tendrá que escuchar estas palabras:

[...] nuestro hogar no ha sido más que un cuarto de recreo. He sido una muñeca grande en esta casa, como fui muñeca en casa de papá. Y a su vez los niños han sido muñecos. Me divertía que jugaras conmigo, como a los niños verme jugar con ellos. Eso es lo que ha sido nuestro matrimonio (Ibsen, 1879: 110).

De nuevo la literatura en el trabajo de Mar Arza, y específicas referencias a la imagen de la casa. Muchas artistas feministas, de uno u otro modo, han acogido este motivo para darle nuevos sentidos. La casa, secularmente el espacio privado de las mujeres, es el lugar donde tantas de ellas viven o han vivido atrapadas. La Nora de Ibsen escapa del secuestro y aunque ni siquiera el paso de los años ha sabido explicar con contundencia la renuncia hacia sus hijos, su nombre sigue siendo una referencia en el proceso de liberación de las mujeres. Es la casa, también, el eje principal en uno de los primeros hitos del arte feminista, la Womanhouse, un espacio retransformado según un proyecto de Judy Chicago y Miriam Schapiro. Compresas manchadas de sangre en el baño, cocina rosada y con pechos de látex en sus paredes, y la instalación Linen Closet de Sandy Orgel, en la que una maniquí, en el armario de las toallas, avanza mientras su cuerpo es atravesado por los estantes del armario, conforman irónicas referencias a lo que dicen que somos.

Hasta hoy mismo, la idea de la casa baña las paredes de la creación feminista. En plástica o literatura, o en la conjunción de ambas. En esa conjunción se sitúa esta idea del útero materno, que es al fin y al cabo la imagen que nos da la vaina como contenedora de semillas. Persistentemente, artistas y escritoras se remiten a aquélla como un contenedor que apresa y sofoca. En el año 2014, la estadounidense Siri Hustvedt vuelve sobre la idea de casa (de sus habitaciones) en la novela El Mundo deslumbrante. Su protagonista es una artista, Harriet Burden que (en un sorprendente juego) oculta su propia obra no ya tras nombres masculinos, sino a través de tres jóvenes artistas varones. Ella, que integra en su obras espacios clausurados de hogares sofocantes, es acusada, cuando firma como mujer, de «pedantería e ingenuidad» (Hustvedt, 2014: 41). No así cuando la firma es masculina. La opinión de la crítica, ya lo sabemos, también está condicionada por el género. Con uno de sus co-artistas elabora Las habitaciones de la asfixia:

La exposición tuvo lugar la primavera después del ataque a Nueva York y el pequeño mutante que salía a rastras del cajón tenía la mirada asustada de un superviviente, de un nuevo ser renacido entre los 
escombros. No importaba que la obra hubiera estado terminada bastante antes de 11 de septiembre. La temperatura que iba creciendo a medida que cruzabas las habitaciones contribuyó a dicha interpretación y, llegado a la última estancia, la atmósfera era agobiante y sombría (Hustvedt, 2014: 151).

Las estancias de una casa, esta vez y de nuevo, convertida en la asfixia que percibíamos en Nora y que vemos en las mujeres-casa de Louise Bourgeois, otro de los referentes de la artista que nos ocupa.

Hasta cierto punto la serie Asombros (2007-2009) de Mar Arza me sugiere también pequeños espacios arquitectónicos de los cuales se escapan las palabras. Son los propios libros, esta vez, los que conforman unas estructuras a modos de pequeñas casas y sorprendentes libros objeto de los que surgen y se entrelazan escultóricamente las palabras, al fin y al cabo: «El reino del libro no tiene sus fronteras entre sus tapas sino que se extiende por la realidad circundante, arraigando castillos en el aire» (Arza, 2007-09).

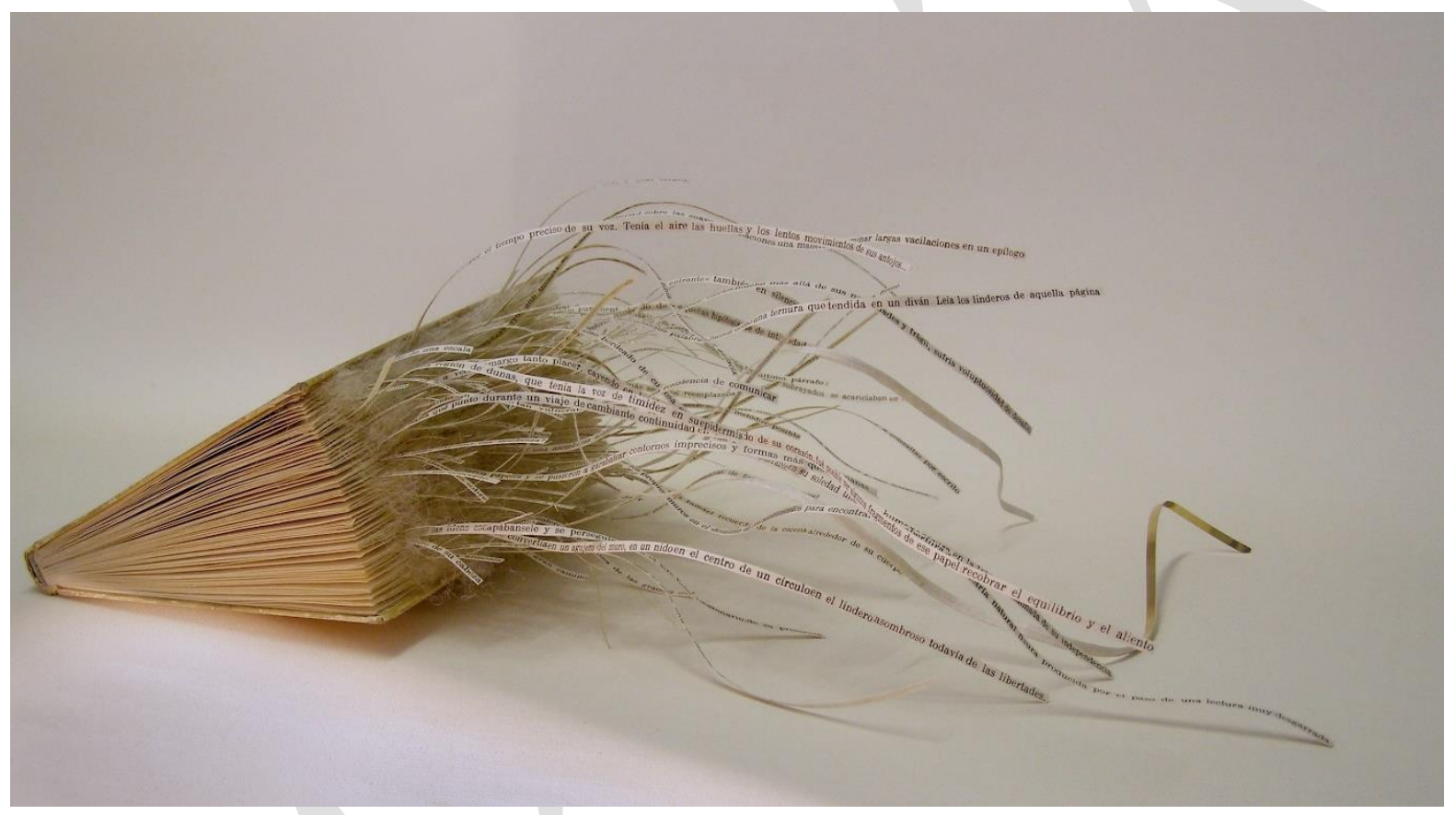

Fig. 5. Serie Asombros. Imagen cortesía de la artista y de la Galería Pilar Dolz.

Constituyen estas obras bellos hallazgos de la artista, que conjuga en ellos tanto la palabra poética como el surrealismo objetual o la praxis escultórica. Dinámicas, la apertura en el espacio de las líneas de palabras, prolongan nuestra mirada más allá de su exacta finitud, en un recurso barroco que paradójicamente nos devuelve una mirada sobria. En cualquier caso, estas obras se adaptan muy bien al concepto de libro-objeto que, para la Modernidad, inició André Breton, quien nos narra:

Una de esas noches, durante el sueño, en un mercado al aire libre que se celebraba cerca de SaintMalo, me encontré con un libro bastante curioso. El lomo de este libro estaba formado por un gnomo de madera cuya barba blanca, cortada a lo asirio, descendía hasta sus pies.

El grosor de la estatuilla era normal y no impedía en nada, pasar las páginas del libro, que eran de gruesa lana negra. Me empeñé en adquirirlo y, al despertarme, lamenté no encontrarlo cerca de mí. Sería relativamente fácil reconstruirlo. Me gustaría poner en circulación algunos objetos de este tipo, cuya suerte me parece particularmente problemática y turbadora (Breton, 1924: 277; la traducción es mía). 
Desde entonces para la Modernidad, pero en realidad desde siempre, el libro ha sido algo más que las palabras en él contenidas. No en vano los códices medievales encerraban en sí maravillosos mensajes excéntricos a la propia historia a través, por ejemplo, de sus hermosas capitulares. Si nos remitimos a cuestiones de género, cómo no nombrar el Salterio de Claricia, en una de cuyas letras iniciadoras de capítulo, una joven que, como indican sus cabellos sueltos, seguramente no había tomado todavía los votos, se columpia alegremente de la letra Q, simulando su rabillo. Ocurría esto entre los siglos XII y XIII. Poco antes, a mitad del XII, una abadesa excepcional, Hildegarda de Bingen, escribe el Scivias (Cómo conocer los caminos del señor), texto, al parecer, parcialmente iluminado por ella. Este libro, como tantos otros, es mucho más que las palabras que contiene; si aquí lo recuerdo especialmente es porque la célebre abadesa aparece citada por la singular autora feminista Faith Wilding en relación con la obra de la artista que analizamos, anunciando:

\footnotetext{
Mar Arza crea lenguaje, crea mundos, con palabras luminosas [...]. Son éstas palabras visionarias, parecidas a las pronunciadas por místicas como Hildegarda de Bingen y Teresa de Ávila, cuyos medios fueron el lenguaje vivaz, las imágenes encendidas y los sonidos plañideros (2013: s/p; la traducción es mía).
}

Solo porque era una «Voz de Dios» o «Voz profética» se prestaba atención en aquella época a mujeres como Hildegarda, que podía asumir prerrogativas que la Iglesia sólo permitía a los varones. Como reconoce Luce Irigaray, el misticismo puede ser contemplado como la única ruptura importante de las polaridades medievales que colocaron a la mujer en una posición subordinada (Chadwick, 1992: 55). Por esta razón, ese misticismo ha pasado a ser un espacio de investigación feminista para analizar las condiciones mediante las cuales las mujeres han tenido que expresarse.

Poderosas lenguas de fuego vienen a posarse, en las ilustraciones del Scivias, sobre la cabeza de Hildegarda. Símbolo del Espíritu Santo, aquellos que las recibían podían hablar en otras lenguas: «Y les aparecieron lenguas como de fuego, que se dividían, y se posaron sobre cada uno de ellos. / Entonces fueron llenados todos del Espíritu Santo, y comenzaron a hablar en otras lenguas, según el espíritu les daba palabras» (Hch, 2: 3-4). Sin relacionar, ni mucho menos, la obra de Mar con la tradición religiosa, sí me ha parecido muy significativo vincularla al pensamiento místico, si no por origen, sí por sensaciones. Porque también son una especie de lenguas de fuego de palabras las que escapan de los libros de Asombros, quizá la serie más hermosa que hasta ahora ha realizado la artista. «En la entraña viva» «Esas palabras» «Este libro»... son grupos de palabras que escapan ondulándose del interior de estos singulares libros-objeto, a modo de las poderosas lenguas de fuego del pensamiento místico. Ahora se comprende el aura que emiten estos libros. Aunque también pueden escapar (y trascender) de ellos tan solo puntos suspensivos, o bien deslizarnos hacia su tejido interior, donde casualmente entrevemos la palabra «entrever». Al fin y al cabo, y en resumen: «El reino del libro no tiene sus fronteras entre sus tapas sino que se extiende por la realidad circundante, arraigando castillos en el aire» (Arza, 2007-09). 


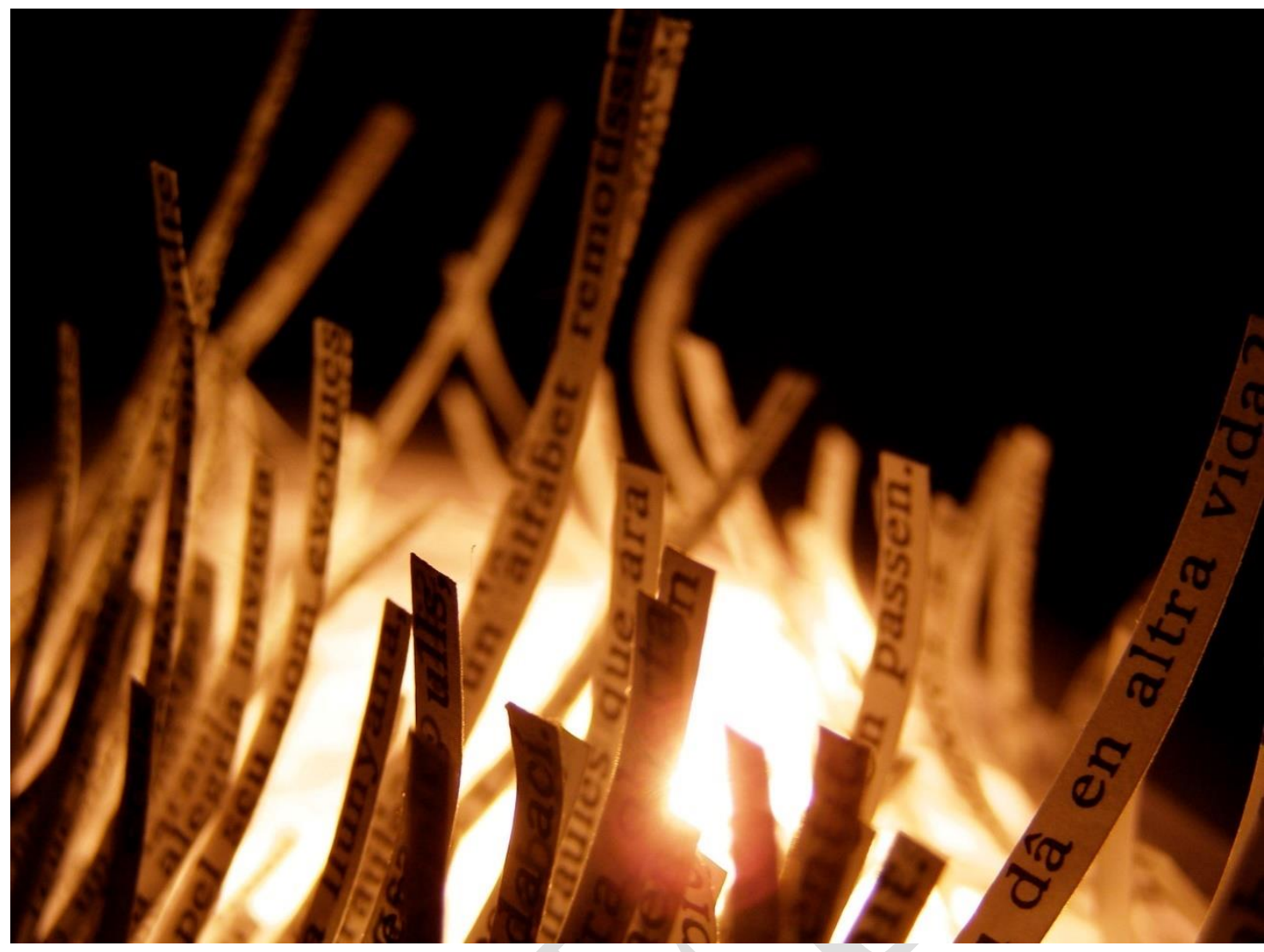

Fig. 6. Serie Lluerna Ulls. Imagen cortesía de la artista y de la Galería Pilar Dolz.

Lluerna ulls, de difícil traducción al castellano en la suma de sus dos palabras (claraboya y ojos) es anterior en el tiempo (se fecha en 2007) a la serie Asombros.

También a esta obra acude la presencia de lo místico. Partiendo de las obras homónimas de Ramón Llul y Vicent Andrés Estellés, Llibre de meravelles, Arza compone dos libros «encendidos» que iluminan el ábside de una capilla de titularidad de Sant Roc, el espacio de arte contemporáneo de la localidad catalana de Valls. No se hubiera producido el mismo resultado en un espacio diferente. La desacralización de la capilla no impide que su pasado y su arquitectura le presten una dimensión vinculada a lo celeste. Pero además, en esta obra, Cèlia del Diego Thomas observa la aparición de una especie personaje fantástico que se suma a los mitológicos castellonenses personificados en Tombatossals, la singular obra de Josep Pascual Tirado:

Presenciamos al tiempo el nacimiento de una nueva figura que se suma a la larga retahíla de personajes fantásticos que pueblan la mitología castellonense. Al lado de los populares Bufa Núvols, Arranca Pins o Traga Pinyols, Lluerna Ulls personifica la mirada serena que nos mira desde la oscuridad para guiarnos a nosotros que, como los personajes de los libros, nos movemos por el espacio buscando el origen de la luz (Diego Thomas, 2014; la traducción es mía).

No es extraño, al fin y al cabo, que la artista tenga recuerdos de los mitos de su propio lugar de origen, puestos sobre el papel por un escritor que supo desarrollar, además de imaginativos personajes, una prosa de calidad, como demuestran aquellas conocidas imágenes-escritura en las que dos accidentes geográficos, Tossal Gros y Penyeta Roja, grande y pequeña colinas o collados, se declaran su amor. Dejamos el texto en su lengua original: «Aromes d'espígol i timonets, de poleo i murta Tossal 
Gros li enviava cap a son indret a Penyeta Roja, i ella, enamorada, en oloroses alenades de saborija i romer, malves i te, li corresponia» ${ }^{1}$ (Pascual i Tirado, 1930: 90). Hermoso fragmento de la historia mítica de Tombatossals, hijo de ambas montañas y gigante de fuerza sobrehumana.

A finales de 2014, Mar Arza participa en la exposición colectiva «Manualmente», organizada por la galería Maserre de Barcelona. De nuevo líneas de palabras y de nuevo un sentimiento general que nos hace comulgar con elevadas dosis de delicadeza y ciertas pautas espirituales. El punto de partida de esta exposición se situaba en una pintora, Josefa Tolrà, Pepeta, una artista que recuerda a las que recogiera magistralmente Dubuffet en su Museo de Art Brut, donde hallamos a una Aloïse Corbaz que nos devuelve unas imágenes femeninas tan nä̈ves como paradójicamente inquietantes. Tolrà, hasta hace bien poco una gran desconocida, a pesar de la admiración que pudiera profesarle Brossa, forma parte de ese grupo de creadoras que pintaron a golpes de tensión psicológica, en estado de trance. Ella, en concreto, pintaba y bordaba:

Del mismo modo que dibuja, sin esbozo previo, Josefa Tolrà también hace bordados. Los motivos y las cenefas se configuran con cada puntada, como resultado de las indicaciones que ella presiente y traslada a la tela. A veces, en esta diligencia exclama: «imira qué me hacen hacer!». Como otras mujeres que han respondido a su potencial psíquico a través de dibujos y tejidos, canaliza los mensajes que llegan desde la dimensión multisensorial con cuidada laboriosidad femenina y doméstica (Bonet, 2014: 267).

Mar, en su manera de acercarse a la artista, traza a su vez palabras sobre la urdimbre de una tela:

Con un ritmo constante el hilo inicia un viaje de ida y vuelta: un hilo color purpúreo -el color adscrito a la espiritualidad - un tanto desvencijado, que se desliza por la urdimbre de hilos blancos más finos, y así, trazo a trazo, va consignando un tejido similar a una página, tensada sobre un bastidor de madera. Una tarea continua que avanza con el curso de los días, las horas y las conversaciones. Una página, trabajo de creación y escritura, en la que parece que podemos alumbrar lo no anunciado (Arza, 2014).

Y entre los hilos, de nuevo sus líneas de palabras, en las que significativamente aparecen: la desgarradura, la grieta, y — también- «demasiadas cosas inquietantes». Mar ha denominado su obra En tela de juicio, el juicio al que se somete a todos y cada uno de nosotros, el que ella misma emprende frente a la manera creativa de una artista que parece sorprenderle tanto cuanto atraerle, pero ante la cual se instala la inquietud y la duda.

En las páginas anteriores hemos abordado aquellas obras donde Mar Arza, a nuestro juicio, más ha tratado con componentes poéticos a través de la palabra (dejamos al margen trabajos tan interesantes como aquellos en los que, jugando con la cotidianidad, reinterpreta facturas, datos bancarios o billetes de lotería). También aquellos otros como Material inflamable, (poderosa construcción que alienta el poder de la palabra) o Trazas y El libro de ahoras [polifonía], en los que el tiempo se sitúa como principal referente. Pero, consecuentemente con la selección establecida, no podemos dejar de mencionar Statement Series, de 2010. Si el soporte libro y/o las palabras nos acompañan en todo el recorrido por la obra de la artista, en este trabajo, fundamentalmente, ha realizado escultura arquitectónica con las líneas extraídas de los libros. A partir de The Silent Pool, de Patricia Wentworth,

\footnotetext{
${ }^{1}$ «Aromas de espliego y tomillos, de poleo y mirto, Tossal Gros enviaba hacia el lugar de Penyeta Roja, y ella, enamorada, en olorosos soplos de ajedrea y romero, malva y té, le correspondía» [Traducción propia].
} 
Mar Arza: la inquietante luz de la palabra

elabora unas preciosas arquitecturas que muy bien podrían rememorar las andanzas constructivistas de El Lissitzky. Cruces de líneas extirpadas del libro, ofreciendo una nueva dimensión a un objeto que es ahora, también, misterio, como los que resuelve Miss Silver, la protagonista de las novelas de la escritora británica que algunos reconocieron como a la nueva Agatha Christie. De nuevo sobre un libro, nuevas historias de Mar.

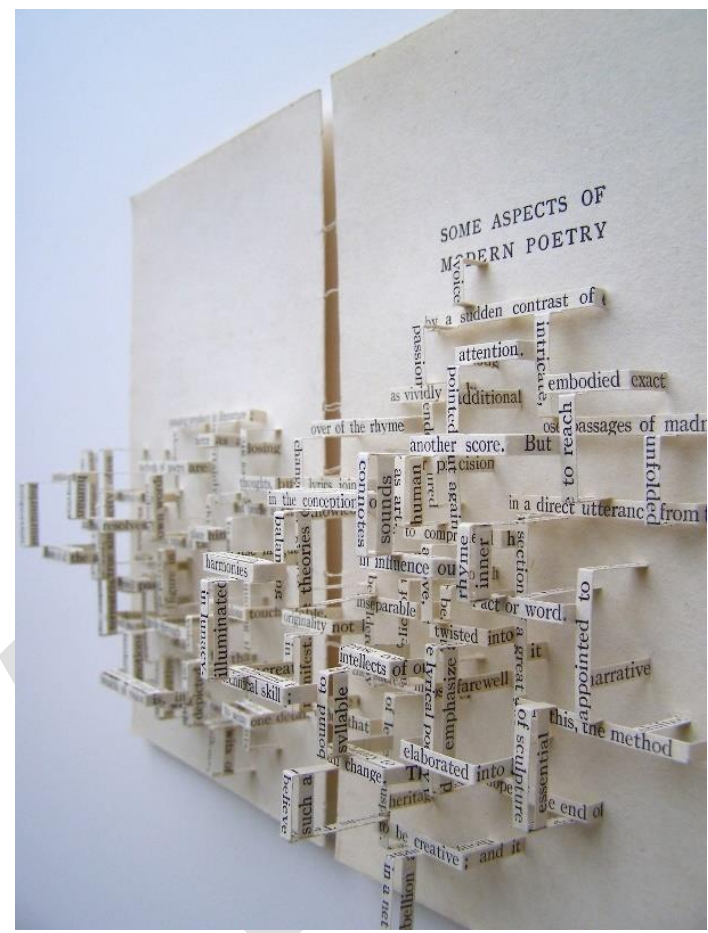

Fig. 7. Statement series. Imagen cortesía de la artista y de la Galería Pilar Dolz

\section{Bibliografía}

ARZA, Mar (2007-09): «¿Dónde ponemos los asombros?», en http://www.mararza.com/ index.php?/2007-2009/asombros/ (última consulta, 2-6-2015).

(2011-13a): «Sutura o aquello que de natural queda en la mística de la feminidad», en http://www.mararza.com/index.php?/2011-2012/femme-gaine/ (última consulta, 2-6-2015).

(2011-13b): «Nora._ ... Sólo sé que mi actitud se me ha hecho indispensable», en http://www.mararza.com/index.php?/2012/femme-gaine/ (última consulta, 2-6-2015).

- (2013): Incís. Barcelona, Duoda / Universitat de Barcelona.

(2014): «Receptáculo de voces», en http://www.mararza.com/index.php?/2014/en-tela-dejuicio/ (última consulta, 2-6-2015).

BASSAS VILA, Assumpta (2003): «letterscape... (with gleanings by the way)», Duoda. Revista d'Estudis Feministes, 24, pp. 244-247.

(2007): En lugar de nada... Mar Arza. Exposició a cura d'Assumpta Bassas Vila. Exposición en La Galeria de Palafrugell, 21 de abril a 10 de junio de 2007. Palafrugell, Ajuntament de Palafrugell.

(2013): «Mar Arza. Momentos radicales: la raíz femenina del corte», en ARZA (2013), s/p.

Bonet, Pilar (2014): «El Pensamiento Lateral del Arte Contemporáneo. Josefa Tolrà, Médium y Artista (1880-1959)», BRAC - Barcelona Research Art Creation. 2/3, pp. 256-276.

BourgeoIs, Louise (1992): Destrucción del padre / reconstrucción del padre. Trad. Rafael Jackson y Pedro Navarro. Madrid, Síntesis, 2002. 
BRETON, André (1924): «Introduction au discours sur le peu de réalité», en Oeuvres complètes. Paris, Gallimard, 1992, vol. II.

Chadwick, Whitney (1990): Mujer, Arte y Sociedad. Trad. María Barberán y Carlos Milla. Barcelona, Destino, 1992.

DiEGo ThOMAs, Cèlia del (2014): «Un món (de llum) rera les paraules», en http://www.mararza.com /index.php?/2007/lluerna-ulls/ (última consulta 13-6-2015).

GRAS, Irene (2013a): «Poeticidad en el lenguaje femenino... charlando con Mar Arza», en http://irenegrascruz.com/2013/02/06/poeticidad-en-el-lenguaje-femenino-charlando-con-mararza (última consulta, 2-6-2015).

_ (2013b) «Poeticidad en el arte. La experiencia de Mar Arza», CBN. Revista de Estética y Arte Contemporáneo, 5, pp. 40-49.

Hustvedt, Siri (2014): El mundo deslumbrante. Trad. Cecilia Ceriani. Barcelona, Anagrama.

IBSEN, Henrik (1879): Casa de muñecas. Ed. Mario Parajón. Madrid, Cátedra, 2007.

KANDINSKY, Wasily (1911): De lo espiritual en el arte. Trad. Genoveva Dieterich. Barcelona, Barral, 1972.

LAFORET, Carmen (1945): Nada. Barcelona, Destino, 1991.

MARINETTI, Filippo Tommaso (1911): «La guerra elettrica», en Marinetti. Teoria e invenzione futurista. Ed. Luciano de Maria. Milán, Mondadori, 1983.

MARTíneZ BENITO, Julia (2011): Kandinsky y la abstracción: nuevas interpretaciones. Salamanca, Universidad de Salamanca, en http://gredos.usal.es/jspui/handle/10366/110540 (última consulta 11/6/2015).

MASÓ, Joana, (2014): «Mar Arza. Lecturas y consumos», en Ciclo blanco sobre negro. Mar Arza. Lecturas y consumos. Barcelona. Santa Mònica. Centre de creativitat, en http://diposit.ub.edu/ dspace/bitstream/2445/51264/1/Mar\%20Arza_CAST.pdf (última consulta 11-6-2015).

Olmo CAMPILlo, Gemma del (2005-06): «La nada como plenitud», en http://www.mararza.com/ index.php?/2005-2008/en-lugar-de-nada/ (última consulta, 13-6-2015).

SAGRADA BIBLIA (1972): Sagrada Biblia. Barcelona: Herder.

SCHREYER, Lothar (1956): Erinnerungen an Sturm und Bauhaus. Munich, Albert Langen.

SEIBERLING, Dorothy (1974): «The Female View of Erotica», New York Magazine, 7/6, pp. 54-58.

PASCUAL I TIRADO, Josep (1930): Tombatossals. València, Tres i Quatre, 1988.

WILDING, Faith (2013): «Silencis lluminosos» en ARZA (2013), s/p. 